Available online at GSC Online Press Directory

GSC Biological and Pharmaceutical Sciences

e-ISSN: 2581-3250, CODEN (USA): GBPSC2

Journal homepage: https://www.gsconlinepress.com/journals/gscbps

(RESEARCH ARTICLE)

\title{
Antimycotic effect of Melaleuca alternifolia on cutaneous mycosis
}

\author{
Onyenwe Nathaniel Ejikeme ${ }^{1}$, Adeniyi-Akee Mukaram Akintunde ${ }^{2,}{ }^{*}$, Akpoyibo Emmamuzo Josphine ${ }^{1}$, \\ Nwofor Chioma Nnena ${ }^{3}$ and Okoro Jude Chidi 4 \\ ${ }_{1}$ Department of pharmaceutical Microbiology, College of pharmacy, Igbinedion University, Okada, Edo state, Nigeria. \\ ${ }^{2}$ Department of pharmaceutical Chemistry, College of pharmacy, Igbinedion University, Okada, Edo state, Nigeria. \\ ${ }^{3}$ Department of Applied Microbiology and Brewing, Faculty of Bioscience, Nnamdi Azikiwe University, Awka, Anambra \\ State, Nigeria. \\ ${ }^{4}$ Department of pediatrics, College of Medicine, Imo State University Teaching Hospital, Owerri, Imo State, Nigeria.
}

Publication history: Received on 29 April 2020; revised on 04 May 2020; accepted on 10 May 2020

Article DOI: https://doi.org/10.30574/gscbps.2020.11.2.0117

\begin{abstract}
Cutaneous fungi in human infections are serious medical threat. Recently, based on reports, numerous fungal species were regarded as natural contaminants. Generally, researchers and other clinicians in the field have deemed it fit and worthy that new potent, effective and safe antifungal drugs are needed. This study reports the antifungal activity of the aqueous extract of Melaleuca alternifolia (tea tree) leaves, using the standard drugs, ketoconazole as the positive control. Antifungal assay was done using Clinical and Laboratory Standard Institutes (CLSI) procedures against isolates such as yeast; Rhodoturular and moulds; Aspergillus flavus, Aspergillus niger and Aspergillus fumigatus. The results showed significant zone of inhibitions ( $>12 \mathrm{~mm}$ and $<25 \mathrm{~mm}$ diameter) for Melaleuca alternifolia compared to ketoconazole ( $>5$ $\mathrm{mm}$ and $<19 \mathrm{~mm}$ ). Cytotoxic test of the crude extract using tadpoles produced mortality of $18 \pm 2.50 \%$ at the lowest concentration of $21.9 \mu \mathrm{g} / \mathrm{ml}$, and $55 \pm 3.40 \%$ at the highest concentration of $175 \mu \mathrm{g} / \mathrm{ml}$ over a 24 hour period. The phytochemical screening of the extract showed the presence of tannins, saponins, flavonoids, alkaloids, cardiac glycosides and terpenes. The in vitro antifungal activities gave remarkable effect on the selected fungi isolates. The remarkable antifungal activity shown by Melaleuca alternifolia methanol extract, against yeast and moulds, suggested its usefulness as a natural antifungal agent for the treatment of some cutaneous mycoses with no cytotoxic effect, and also highlights its significance use as potential healthcare product in pharmaceutical formulations when adopted.
\end{abstract}

Keywords: Antifungal; Tea tree oil (TTO); Melalueca alternifolia; Cytoxicity; Zone of inhibitions

\section{Introduction}

Cutaneous fungi infection poses serious medical issues and more than a hundred thousand fungal species have been considered as natural contaminants [1]. Therefore, it is quite logical that any recent search for new prototype antifungal products should also include a variety of plant extracts [2]. Also, to design a search for novel prototype antifungal agent, it seems reasonable to assume that if new agents are found to have different structures and different activities from those in current use, higher plants are a logical choice, chiefly because of their seemingly infinite variety of novel molecules, which are often referred to as secondary metabolite [2]. Antifungal agents are widely distributed among higher plants [3], but only a few have been evaluated for their activity against human pathogenic fungi. In the past few decades, a worldwide increase in the incidence of fungal infections has been observed as well as a rise in the resistance of some species of fungi to conventional antifungal drugs used in medical practice. Therefore, new prototype antimicrobial agents are needed to address this situation [4].

\footnotetext{
* Corresponding author: Adeniyi-Akee Mukaram Akintunde, Phone: +2348067714939 Email: mukkyakee@yahoo.com
} 
Fungi are one of the most neglected pathogens as demonstrated by the fact that the amphotericin B, a polyene antibiotic discovered as long as 1956, is still used as a gold standard for antifungal therapy [5]. Exploitation of naturally occurring compounds from plants and microbes have been suggested [6]. The majority of clinically used antifungal agents have various draw backs in terms of toxicity, efficacy as well as cost and their frequent use has led to emergence of resistant strains. Hence there is a great demand for novel antifungal drugs belonging to a wide range of structural classes, selectively acting on new targets with least side effects. Natural products, either as pure compounds or as standardized plant extracts, provide unlimited opportunities for new drug leads. In addition, edible plants have been proven to be harmless and are economical [7], in which one of them is the tea tree known as Melaleuca alternifolia.

Comprehensive investigation of the susceptibility of fungi to the oil of Melaleuca alternifolia has only recently been completed $[8,9]$. Prior to this, data were somewhat piecemeal and fragmentary. Early data were also largely limited to Candida albicans, which was a commonly chosen model test organism. Recently, data now shows that a range of yeasts, dermatophytes, and other filamentous fungi are susceptible to TTO [10]. Although test methods differ, minimum inhibitory concentration (MICs) generally range between 0.03 and $0.5 \%$, and fungicidal concentrations generally range from 0.12 to $2 \%$. The notable exception is Aspergillus niger, with minimal fungicidal concentrations (MFCs) of which are as high as $8 \%$ reported for this organism [11]. However, these assays were performed with fungal conidia, which are known to be relatively impervious to chemical agents. Subsequent assays have shown that germinated conidia are significantly more susceptible to TTO than non-germinated conidia [10], suggesting that the intact conidial wall confers considerable protection. TTO vapors have also been demonstrated to inhibit fungal growth and affect sporulation [12]. Studies investigating the mechanisms of antifungal action have focused almost exclusively on C. albicans. Similar to results found for bacteria, TTO also alters the permeability of $C$. albican cells. The treatment of $C$. albicans with $0.25 \%$ TTO resulted in the uptake of propidium iodide after $30 \mathrm{~min}$ [13], and after 6 hours significant staining with methylene blue and loss of $260 \mathrm{~nm}$ light-absorbing materials had occurred [14]. TTO also inhibits respiration in $C$. albicans in a dose-dependent manner [15]. Additional studies have shown that when cells of $C$. albicans are treated with diethyl stilbestrol to inhibit the plasma membrane ATPase, they had a much greater susceptibility to TT0 than control cells [9], suggesting that the plasma membrane ATPase has a role in protecting cells against the destabilizing or lethal effects of TTO. Tea Tree Oil inhibits the formation of germ tubes, or mycelial conversion, in C. albicans [16]. Two studies have shown that germ tube formation was completely inhibited in the presence of 0.25 and $0.125 \%$ TTO, and it was further observed that treatment with $0.125 \%$ TTO resulted in a trend of blastospores changing from single or singly budding morphologies to multiply budding morphologies over the 4-hour test period [17]. These cells were actively growing but were not forming germ tubes, implying that morphogenesis is specifically inhibited, rather than all growth being inhibited. Interestingly, the inhibition of germ tube formation was shown to be reversible, since cells were able to form germ tubes after the removal of the TTO [17]. However, there was a delay in germ tube formation, indicating that TTO causes a post antifungal effect.

Tea tree oil possessed antifungal activity against filamentous fungi associated with invasive fungal wound infections (IFIs); and it indicated a potential use as topical treatment of IFIs [18]. The study of in-vitro susceptibilities of candida and Aspergillus species to melaleuca alternifolia (tea tree) oil [19] showed that Melaleuca alternifolia inhibited the candida species. Thus, this study investigates the effects of the crude aqueous extract of the tea tree Melaleuca alternifolia on cutaneous mycosis.

\section{Material and methods}

\subsection{Extraction of the plant}

The leaves of Melaleuca alternifolia were air-dried under shade, at room temperature $\left(20-25^{\circ} \mathrm{C}\right)$, for 3 weeks. The dried leaves were grinded into powder (340 g), using laboratory milling machine. The dried powder was cold-macerated using distilled water for 48 hours. The liquid extract was filtered and then concentrated using rotary evaporator at 40 ${ }^{\circ} \mathrm{C}$, and to complete dryness inside fume cupboard. The concentrated and dried extract which weighed $7.7 \mathrm{~g}$ was stored in a sample bottle and refrigerated prior to bioassay work.

\subsection{Phytochemical screening}

The plant extract was assessed for the presence of phytochemicals using method described by [20].

\subsection{Preparation of fungal strains}

Viability tests were carried out by picking the organism from the stock using sterile loop and inoculated into sabouraud dextrose agar (SDA) media and then left at room temperature. The test fungi were confirmed using morphological and microscopic characteristics, using direct plate culture method and slide culture techniques respectively. 


\subsection{Morphological / microscopic characterization of fungi isolates}

The identification of the isolated fungi organism was done by slide culture technique. $10 \mathrm{ml}$ of glycerol was added into a beaker containing $25 \mathrm{ml}$ of sterile distilled water. A folded whatman filter paper was soaked into the beaker and placed in a sterile plate. A slide was placed on the whatman paper as a base. Using a sterile blade, sabouraud dextrose agar (SDA) was cut into squares (block) small enough to fit under a cover slip. A square of the agar was placed in the middle of the slide in the plate and the fungal isolates were inoculated on the cut agar block on the slide. Then a cover slip was placed on the agar block on the slide, which was placed on the whatman filter paper in the sterile petri dish and left under room temperature for 2 days until growth and sporulation has occurred.

After visible growth, the cover slip was removed and 2 drops of lactophenol cotton blue was placed on the agar block and then the cover slip was placed back onto the wet agar block. The slide containing the wet agar block was examined under the microscope at $\mathrm{x} 40$. This procedure was repeated for each fungus isolate in other to view their conidia, hyphae and micro conidia.

\subsection{Molecular identification of test organism}

Fungal isolates were obtained from skin scraping from skin of infected cows from abattoirs' in Owerri, Imo state, Nigeria. The exudates from the skin scrapings were cultured using SDA and incubated for 2-5 days and their Molecular Identification were verified using the 16S RNA primer and gene sequencing. The isolates include, Aspergillus niger, aspergillus fumigatus, aspergillus flavus and rhodoturular specie.

\subsection{Preparation of Mcfarland standard}

Mcfarland standard is used as a reference to adjust the turbidity of fungal suspension so that fungal organisms will be within a given range. Accurately 0.5 Mcfarland equivalent turbidity was prepared by adding $0.6 \mathrm{ml}$ of $1 \%$ Barium chloride solution $\left(\mathrm{BaCl}_{2} .2 \mathrm{H}_{2} \mathrm{O}\right)$ to $99.4 \mathrm{ml}$ of $1 \%$ Tetraoxosulphate acid $\left(\mathrm{H}_{2} \mathrm{SO}_{4}\right)$ and mixed thoroughly. Then, a small of the turbid solution was transferred to a cap tube of the same type that was used to prepare the test organism and control inoculum. It was then stored in the dark at room temperature $\left(25^{\circ} \mathrm{C}\right)$. Exactly 0.5 Mcfarland gives an equivalent approximate density of fungi $1.5 \times 10^{8}$ colony forming units per $\mathrm{ml}(\mathrm{CFU}) \mathrm{mL}^{-1}$ [21].

\subsection{Preparation of extract}

$2.5 \mathrm{~g}$ of crude extract was weighed into $25 \mathrm{ml}$ sterile distilled water $(100 \mathrm{mg} / \mathrm{ml})$ and was mixed for 30 minutes in an electric shaker, to obtain a homogenous solution. Then, the extract was filtered using whatman No.1 filter paper to exclude the granules. The extract solution was transferred into a sterile screw cap bottle and labeled stock solution, then stored in the refrigerator $\left(4^{\circ} \mathrm{C}\right)$.

\subsection{Disc diffusion method}

The use of agar disc diffusion method to screen for antifungal activities of the crude tea aqueous extract was done accordingly to the National Committee of Clinical and Laboratory Standards [22] now Clinical and Laboratory Standard Institutes (CLSI). The fungal inoculums for susceptibility test were standardized using barium sulphate standard equivalent to McFarland No 0.5, giving cell density of $1.5 \times 10^{8}$ Colony Forming Units per ml (CFU/ml). Circular paper discs (6mm diameter) made of whatman No.1 filter paper were prepared with the aid of an office paper perforator. The discs were placed in a petri-dish and sterilized in an autoclave. Dilutions of several concentrations of the crude extracts were made. A Positive control was made using azole group of compound (ketoconazole), and the negative control were prepared using sterile distilled water. Blank sterile papers disc measuring $6 \mathrm{~mm}$ were impregnated with $20 \mu \mathrm{L}$ of test concentration of crude extract. The discs were then aseptically transferred into respective inoculated plates. Briefly, approximately $1.5 \times 10^{8}$ cells of freshly grown fungal suspension were uniformly streaked in the sterile malt extract agar dishes using wire loop. The discs with respective crude extract solution concentrations were placed on a Malt extract agar plates containing chloramphenicol to which the test fungi have been inoculated. The inoculated plates were left for 48 hours before the activity was determined. The activities of the crude extract were established by the presence of zones of inhibition which were measured in millimeter. ketoconazole discs were used as antifungal reference standards for positive control. Similarly, the sterile distilled water was set as negative controls.

\subsection{Well in agar diffusion method}

2 drops of diluted inoculum with different concentration was placed into different sterile cap bottle containing $15 \mathrm{ml}$ of sterilized malt extract agar and chloramphenicol. They were mixed and transferred into sterile plates respectively and allowed to solidify. Using a sterile cock borer, holes were made in the agar plate and labeled according to concentrations. Different concentration was poured into the holes respectively. This procedure was done for the antifungal drugs 
ketoconazole and the extracts with different dilutions of the drug. These plates were left for 48 hours before observation for the zone of inhibition.

\subsection{Cytotoxic assay of crude extract using tadpoles (Ranicepsranninus)}

Tadpoles (5-7 days old) were scooped from fresh water in the crown estate, Okada, Edo State, Nigeria; and were properly identified in the Department of Animal and Environmental Biology, Faculty of Life Science, University of Benin, Edo State, Nigeria. 10 tadpoles of same sizes together with $30 \mathrm{~mL}$ of their habitat water were transferred into different beakers. Distilled water was added to make contents up to $49 \mathrm{~mL}$, after which $1 \mathrm{~mL}$ of each concentration (175, 87.5, $43.7,21.9 \mu \mathrm{g} / \mathrm{ml}$ ) of the extract in 5\% dimethyl sulfoxide (DMSO) was added to make the mixtures up to $50 \mathrm{~mL}$ [23]. The experiments were incubated for 24 hours after which mortality was determined. Control assay was done with 50 $\mathrm{mL}$ of habitat water containing $1 \mathrm{~mL}$ of $5 \%$ DMSO in distilled water. All tests were done in triplicate.

\section{Results and discussion}

The phytochemical analysis of the plant extracts which yielded $2.26 \%$ was shown in table 1 . Table 2 showed the Cutaneous fungi isolates of the macroscopic and microscopic identification of the test organism A, B, C and D with their diagrams. Figure 1 shows a chart presentation of the in vitro antifungal activity of crude aqueous extract of melaleuca alternifolia using agar well diffusion method.

Table 1 Phytochemical constituents of crude aqueous extract Melaleuca alternifolia sample.

\begin{tabular}{lll}
\hline S/N & Phytochemical compound & Result \\
\hline 1 & Saponins & + \\
2 & Terpenes & + \\
3 & Flavonoids & + \\
4 & Alkaloids & + \\
5 & Cardiac glycoside & + \\
6 & Tannins and phenolic compounds & + \\
7 & Phenols & + \\
8 & Anthraquinones & - \\
\hline & $+=$ indicates the presence, while - = indicates the absence
\end{tabular}

The identification of the plant Melaleuca alternifolia (table 2) was done by macroscopic and microscopic (A2, B2, C2 and D2) characteristics; macroscopic identification was done by color, shape and texture. Microscopic examination was done by slide culture technique and the fungal indicated includes Rhodotorulasp, Aspergillus fumigatus, Aspergillus flavus, Aspergillus niger.

Table 2 Cutaneous fungi isolates of the macroscopic and microscopic identification of the test organism A, B, C and D with their diagrams.

\begin{tabular}{|c|c|c|}
\hline Fungi Samples & Macroscopic/microscopic Examination of isolates & Identified isolates \\
\hline A & $\begin{array}{l}\text { Colonies with previously creamy white surface which turns } \\
\text { ink to wine, having reverse side pink to wine colorations on } \\
\text { SDA. They Produce conidia }\end{array}$ & $\begin{array}{l}\text { Rhodotorula } \\
\text { (yeast) }\end{array}$ \\
\hline B & $\begin{array}{l}\text { Colonies previously white cotton like surface with radial } \\
\text { segments, which gradually turn greyish green with white at } \\
\text { the edge, having reverse side creamy yellow and radial } \\
\text { segmented. They Produce conidia }\end{array}$ & $\begin{array}{l}\text { Aspergillus } \\
\text { fumigatus }\end{array}$ \\
\hline $\mathrm{C}$ & $\begin{array}{l}\text { Colonies previously white cotton like surface with radial } \\
\text { segments, which gradually turn bluish green with white at } \\
\text { the edge, having reverse side creamy yellow and radial } \\
\text { segmented. They Produce conidia and filaments }\end{array}$ & Aspergillus flavus \\
\hline $\mathrm{D}$ & $\begin{array}{l}\text { Colonies previously white cotton like surface with radial } \\
\text { segments, which gradually turn black with white at the edge, } \\
\text { having reverse side creamy yellow and radial segmented. } \\
\text { They Produce conidia and filaments. }\end{array}$ & Aspergillus niger \\
\hline
\end{tabular}




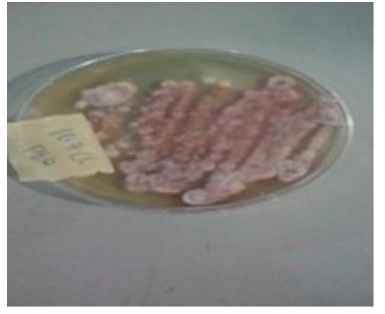

A1

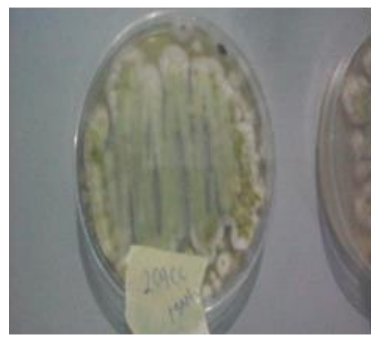

C1

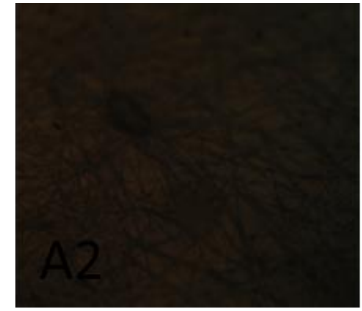

$\mathrm{A} 2$

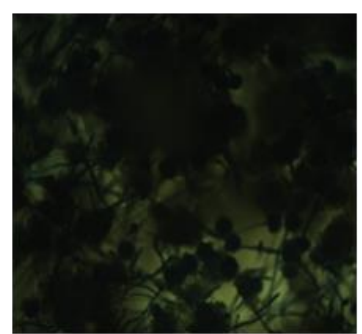

$\mathrm{C} 2$

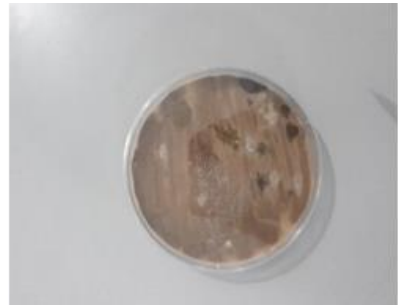

B1

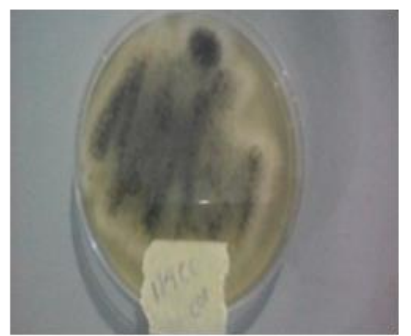

D1

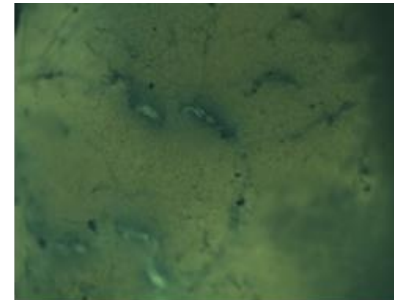

B2

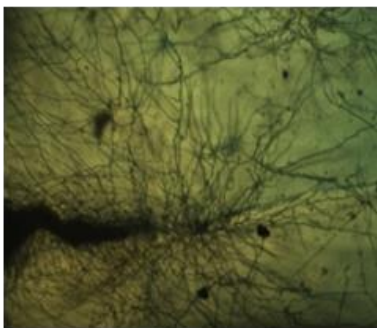

D2

A1 = Macroscopy of Rhodotorular (yeast)

A2 = Microscopy of Rhodotorular (yeast)

B1 = Macroscopy of Aspergillus fumigatus

B2 = Microscopy of Aspergillus fumigatus

C1 = Macroscopy of Aspergillus flavus

C2 = Microscopy of Aspergillus flavus

D1 = Macroscopy of Aspergillus niger

D2 = Microscopy of Aspergillus niger

The antifungal activity of (Melaleuca alternifolia) crude aqueous extracts, using well diffusion method, at concentration levels; $100 \mathrm{mg} / \mathrm{mL}, 50 \mathrm{mg} / \mathrm{mL}$ and $25 \mathrm{mg} / \mathrm{mL}$ were presented in fig 1 ,

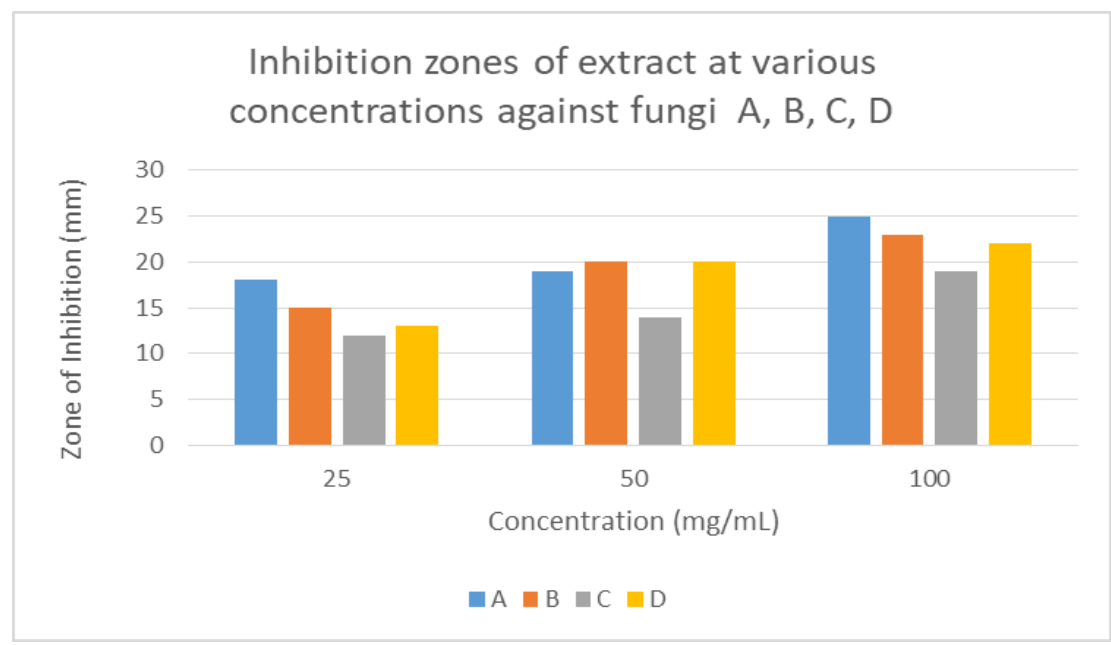

$\mathrm{A}=$ Rhodotorular (yeast), $\mathrm{B}=$ Aspergiluus fumigatus, $\mathrm{C}=$ Aspergillus flavus, $\mathrm{D}=$ Aspergillus niger .

Figure 1 Zone of Inhibition ( $\mathrm{mm}$ ) of crude aqueous extract of melaleuca alternifolia at various concentrations against fungal organisms A, B, C, D., using well diffusion method.

Concentration of $100 \mathrm{mg} / \mathrm{mL}$ exhibited more zone of inhibition for organism A with $25 \mathrm{~mm}$, followed by organism $\mathrm{D}$ (23 $\mathrm{mm})$, organism B (22 $\mathrm{mm})$, organism C (19 $\mathrm{mm})$ respectively. 
For concentration $50 \mathrm{mg} / \mathrm{mL}$, organism B and D exhibited more zone of inhibition with 20 mm each followed by organism A with $19 \mathrm{~mm}$ and organism $\mathrm{C}$ with $14 \mathrm{~mm}$.

For concentration of $25 \mathrm{mg} / \mathrm{mL}$, organism A with $18 \mathrm{~mm}$ showed more zone followed by organism B with $15 \mathrm{~mm}$, organism D with $13 \mathrm{~mm}$ and organism $\mathrm{C}$ with $12 \mathrm{~mm}$ respectively.

The antifungal activity of ketoconazole (Standard Drug), using well diffusion method at concentration of $20 \mathrm{mg} / \mathrm{mL}, 10$ $\mathrm{mg} / \mathrm{mL}$ and $5 \mathrm{mg} / \mathrm{mL}$ to the test organisms are presented in fig. 2.

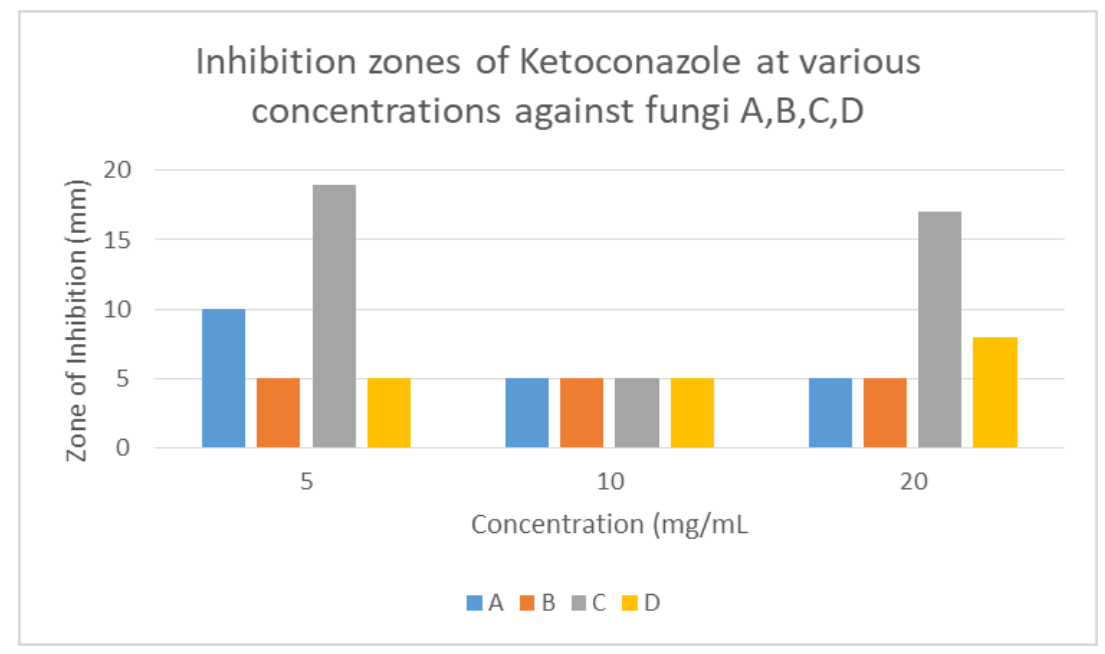

$\mathrm{A}=$ Rhodotorular (yeast), $\mathrm{B}=$ Aspergillus fumigatu, $\mathrm{C}=$ Aspergillus flavus, $\mathrm{D}=$ Aspergillus niger

Figure 2 Zones of Inhibition (mm) of Ketoconazole at various concentrations against fungal organisms A, B, C, D., using well diffusion method.

For organism A, the concentration of $5 \mathrm{mg} / \mathrm{mL}$ showed greater zone of inhibition with $10 \mathrm{~mm}$, then the concentrations $20 \mathrm{mg} / \mathrm{mL}$ and $10 \mathrm{mg} / \mathrm{mL}$ had no zone of inhibition, thus, there was resistance ( $5 \mathrm{~mm}$ diameter is estimated (considered) as no zone of inhibition).

The organism B is resistant to the antifungal drug (ketoconazole) at all concentrations (5mm is considered as no zone of inhibition).

For organism $\mathrm{C}$, the concentration $5 \mathrm{mg} / \mathrm{mL}$ had greater zone of inhibition with $19 \mathrm{~mm}$, then concentration $20 \mathrm{mg} / \mathrm{mL}$ had $17 \mathrm{~mm}$; but concentration $10 \mathrm{mg} / \mathrm{mL}$ is resistant with no zone ( $5 \mathrm{~mm}$ is considered as no zone of inhibition).

For organism D, concentration $20 \mathrm{mg} / \mathrm{mL}$ showed zone of inhibition with $8 \mathrm{~mm}$ and $10 \mathrm{mg} / \mathrm{mL}$ and $5 \mathrm{mg} / \mathrm{mL} \mathrm{showed}$ no zone of inhibition.

The antifungal activity of ketoconazole with various concentrations of $20 \mathrm{mg} / \mathrm{mL}, 10 \mathrm{mg} / \mathrm{mL}, 5 \mathrm{mg} / \mathrm{mL}, 2.5 \mathrm{mg} / \mathrm{mL}$, $1.25 \mathrm{mg} / \mathrm{mL}, 0.625 \mathrm{mg} / \mathrm{mL}, 0.3125 \mathrm{mg} / \mathrm{mL}$ using a disc of $6 \mathrm{~mm}$ in disc diffusion method are presented in fig. 3 . The inhibitory effect against the four organisms; A, B, C, D (dermatophytes) were taken by their zones of inhibition (mm).

Organism A, at concentration of $2.5 \mathrm{mg} / \mathrm{mL}$ exhibited more zone of inhibition with diameter $22 \mathrm{~mm}$ followed by concentration $0.625 \mathrm{mg} / \mathrm{mL}$ at $20 \mathrm{~mm}$, then $5 \mathrm{mg} / \mathrm{mL}$ at $16 \mathrm{~mm}, 1.25 \mathrm{mg} / \mathrm{mL}$ with $14 \mathrm{~mm}$ and $20 \mathrm{mg} / \mathrm{mL}, 10 \mathrm{mg} / \mathrm{mL}$ and $0.325 \mathrm{mg} / \mathrm{mL}$ with no zone of inhibition ( $5 \mathrm{~mm}$ diameter is estimated (considered) as no zone of inhibition).

For organism $\mathrm{B}$, concentration at $2.5 \mathrm{mg} / \mathrm{mL}$ exhibited the highest zone of inhibition with $15 \mathrm{~mm}$ diameter, then concentrations at $20 \mathrm{mg} / \mathrm{mL}, 10 \mathrm{mg} / \mathrm{mL}, 5 \mathrm{mg} / \mathrm{mL}, 1.25 \mathrm{mg} / \mathrm{mL}, 0.625 \mathrm{mg} / \mathrm{mL}$, and $0.3125 \mathrm{mg} / \mathrm{mL}$ showed no zone of inhibition. 


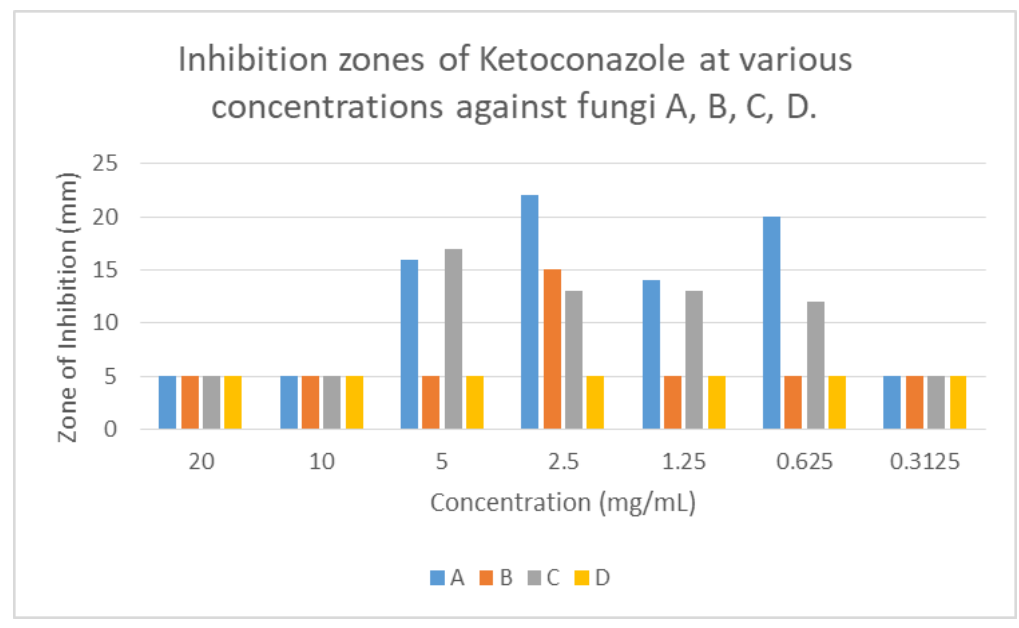

$\mathrm{A}=$ Rhodoturula (yeast), $\mathrm{B}=$ Aspergillus fumigatu, $\mathrm{C}=$ Aspergillus flavus, $\mathrm{D}=$ Aspergillus niger

Figure 3 Zones of Inhibition (mm) of Ketoconazole at various concentrations against fungal organisms A, B, C, D., using disc diffusion method.

For organism $\mathrm{C}$, concentration at $5 \mathrm{mg} / \mathrm{mL}$ exhibited the highest zone of inhibition with $17 \mathrm{~mm}$ diameter, followed by concentrations at $2.5 \mathrm{mg} / \mathrm{mL}$ and $1.25 \mathrm{mg} / \mathrm{mL}$ with $13 \mathrm{~mm}$ diameter each, then $0.625 \mathrm{mg} / \mathrm{mL} \mathrm{with} 12 \mathrm{~mm}$, concentrations at $20 \mathrm{mg} / \mathrm{mL}, 10 \mathrm{mg} / \mathrm{mL}$ and $0.3125 \mathrm{mg} / \mathrm{mL}$ showed no zone of inhibition.

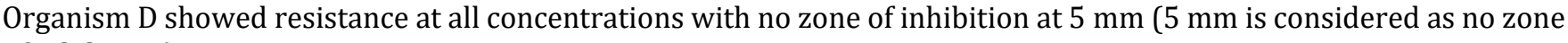
of inhibition).

The effects of the aqueous extract of Melaleuca alternifolia leaves on tadpole mortality was presented in figure 4. The stock solution of the crude aqueous extract was made in different concentrations and accessed for its mortality. The leaves extract produced mortality (Values are Mean \pm S.E.M.) of $18 \pm 2.50 \%$ at the lowest concentration of $21.9 \mu \mathrm{g} / \mathrm{ml}$ and $55 \pm 3.40 \%$ at the highest concentration of $175 \mu \mathrm{g} / \mathrm{ml}$. The mortality results were dose- dependent over a period of 24 hours. The lethal effects of plant extracts on tadpoles (Ranicepsranninus) is a bench-top assay method used to investigate their preliminary cytotoxic effect [24]. The method is simple, reproducible and tadpoles are not far fetch.

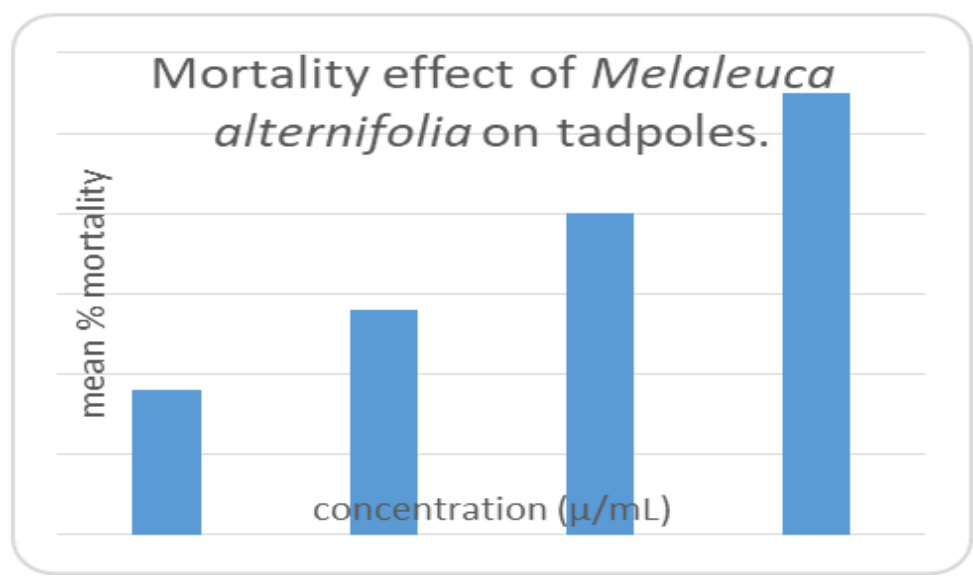

Figure 4 Chart representation of the mean \% mortality of Melaleuca alternifolia on tadpoles.

Shift in the treatment of infectious diseases is necessary where appropriate alternatives to antibiotics ought to be considered, and also to prevent antibiotics from becoming obsolete. There are already several non-antibiotic approaches to the treatment and prevention of infection, including probiotics, phages, and phytomedicines. Melaleuca alternifolia is an old, over the counter remedy that possesses in vitro antifungal activity against a broad spectrum of candida species [25]. It has antibacterial and antifungal activity properties that have secured it a place in the commercial pharmaceutical market. Melaleuca compounds may be a valuable addition to the management of fungal infections in the future [10]. 
For all the organism tested in this study, organism A (Rodotorula), a yeast was the most sensitive fungus to the crude extract, organism B (Aspergillus flavus), D and C also showed great inhibitions sequentially, using well in agar method. For other assay method used, such as disc diffusion, the entire test organisms used were resistant. Therefore, assay method could also affect the result of any activity of drugs on organism, especially fungi.

Our results indicate a considerable difference in antifungal (antimycotic) of Melaleuca alternifolia and that of the standard antifungal drug (ketoconazole), which confirms that the crude aqueous extract has antimicrobial effect against the test organism (organism A,B,C,D) using pour plate method/well in agar. Organism A was the most sensitive fungus to the crude extract of Melaleuca alternifolia. For the antimicrobial activity of ketoconazole, organism D showed greater sensitivity than the other organisms used. The result of the comparative analysis of the extract and ketoconazole using pour plate method/well in agar method showed that, the extract of the plant showed more antifungal activity against the test organisms than ketoconazole. Extract activity with the test organism A (Rhodotorula) which is a yeast, showed greater zone of inhibition diameter of $>18 \mathrm{~mm}$, while organism D (Aspergillus niger) was moderately sensitive with inhibition zone diameter of $>13 \mathrm{~mm}$, followed by organism B with zone of inhibition $>15 \mathrm{~mm}$, and then organism $\mathrm{C}$ having $>12 \mathrm{~mm}$ zone of inhibition. While for ketoconazole activities, organism D showed greater inhibition zone $<19$ $\mathrm{mm}$, and organism B was resistant with inhibition of zone diameter of $5 \mathrm{~mm}$. The results in this study were in line with the report of [26], where it was stated that ketoconazole is not useful in treating aspergillosis, zygomycosis or sporotrichosis. Due to the concentration of ketoconazole used, the organisms exhibited more resistant than sensitivity to the antifungal drug.

Tea tree oil, as a direct contact solution, was the most effective at inhibiting fungal growth of both test species among all the agents assessed in the current study. This result is in agreement with previously published data on the in vitro antimicrobial efficacy of TTO from a clinical setting [17], where it was found that TTO had both an inhibitory effect and a fungicidal effect on filamentous fungi. The authors found both germinated conidia and non-germinated conidia of the fungal isolates demonstrated susceptibility to TTO. The mechanism of TTO's antifungal action is believed to be by the alteration of the cell membrane structure, causing it to become permeable, which leads to the leakage of cellular material and disruption to cellular functions [17].

The phytochemical study revealed the presence of tannins, saponins, alkaloids, cardiac glycosides, terpenes, flavonoids and phenols (Table 1). These are significant components that are capable of causing varied physiochemical and pharmacological effects [27]. The results were in line with similar studies carried out [28], who also reported the presence of saponins, flavonoids, phytosterols, triterpenoids, phenolics and tannins in the leaves extracts of Melaleuca alternifolia. Phytochemical screening, apart from revealing the metabolites responsible for activities, can also help to disclose new sources for vital economical secondary metabolite materials, as a precursor for the synthesis of complex chemical substances [29].

In addition, comparison of our data with those previously published, demonstrate very similar susceptibility results. Unfortunately, it is difficult to compare data from different investigators [17] since the chemical composition may differ or other environmental factors could also affect the components of the drugs used.

\section{Conclusion}

Melaleuca alternifolia crude aqueous extract had greater zone of inhibition to the test organisms than the test antifungal drug, ketoconazole, which showed that it is more active in the treatment of the test organisms used in this study than ketoconazole. This plant can therefore be utilised as an alternative source of useful antifungal drugs.

\section{Compliance with ethical standards}

\section{Acknowledgments}

The authors are grateful to the Department of pharmaceutical microbiology, College of Pharmacy, Igbinedion University, Okada, Edo state, for granting permission to conduct the anti-fungal assay reported in this study. The authors are also thankful to Kingsley Adibe Mbachu of the Department of Chemistry, University of Ibadan.

\section{Disclosure of conflict of interest}

Authors declared no competing interests. 


\section{References}

[1] Kacaniova M. (2003). Feeding soybean colonization by microscopic fungi. Trakya University. Journal of Science, 56(4), 165-168.

[2] William LW, Sylvia LB, Joy DJ, Scott SJ, Clark H and Alfred TL. (1992). Herpes Simplex Virus in Childhood Erythema Multiforme. Pediatrics, 89(1), 32-34.

[3] Caceres A, Jauregui E, Herrera D and Logemann H. (1991). Plants used in Guatemala for the treatment of dermato mucosal infections: Screening of 38 plants extracts for anticandidal activity. Journal of Ethanopharmacology, 33(3), 277-283.

[4] Savita J and Sati SC. (2010). Antibacterial potential of leaf extracts of Juniperus communis L. from Kumaun Himalaya. African journal of microbiology research, 4(12), 1291-1294.

[5] Abad MJ, Ansuategui M and Bermejo P. (2007). Active antifungal substances from natural sources. ARKIVOC, 7, 116-145.

[6] Sati SC and Arya P. (2010). Antagonism of some aquatic hyphomycetes against plant pathogenic fungi. Scientific World Journal, 10, 760-765.

[7] Lee DW. (2003). Landscape ecological comprehension and proposal of Village Forests. Forest and Culture, 12(1), 18-35.

[8] Griffin SG, Markham JL and Leach DN. (2005). An agar dilution method for the determination of the minimum inhibitory concentration of essential oils. Journal of Essential Oil Research, 12, 249-55.

[9] Carson CF, Hammer KA and Riley TV. (2006). Melaleuca alternifolia (Tea Tree) Oil: A Review of Antimicrobial and Other Medicinal Properties. Clinical Microbiology Reviews, 19(1), 50-62.

[10] Nenoff P, Herrmann J and Graser Y. (2007). Trichophyton Mentagrophytes interdigitale, A dermatophyte in the course of time. JDDG, 5, 198-202.

[11] Hammer KA, Carson CF and Riley TV. (2012). Influence of organic matter, cations and surfactants on the antimicrobial activity of Melaleuca alternifolia (tea tree) oil in vitro. Journal of Applied Microbiology, 86, 446-52.

[12] Inouye S, Tsuruoka T, Watanabe M, Takeo K, Akao M, Nishiyama Y and Yamaguchi H. (2011). Inhibitory effect of essential oils on apical growth of Aspergillus fumigatus by vapour contact, Mycoses, 43, 17-23.

[13] Cox SD, Mann CM, Markham, JL, Bell HC, Gustafson JE, Warmington JR and Wyllie SG. (2007). The mode of antimicrobial action of the essential oil of Melaleuca alternifolia (tea tree oil). Journal of Applied Microbiology, $88,170-175$.

[14] Hammer KA, Carson CF and Riley TV. (2004). Antifungal effects of Melaleuca alternifolia (tea tree) oil and its components on Candida albicans, Candida glabrata and Saccharomyces cerevisiae. J. Antimicrobial Chemotherapy, 53, 1081-1085.

[15] Summerbell RC. (2003). Trichophyton, Microsporum, Epidermophyton.and agents of superficial mycoses. In: Murray PR, Baron EJ, Jorgensen JH, Pfaller MA and Yolken RH. Manual of clinical microbiology, 2, 1798-1819.

[16] D'Auria L, Giudicepietro F, Martini M and Lanari R. (2012). The 4D imaging of the source of ground deformation at Campi Flegrei caldera (southern Italy). Journal of Geophysical Research Atmospheres, 117(B8).

[17] Hammer KA, Carson CF and Riley TV. (2008). In vitro activity of Melaleuca alternifolia (tea tree) oil against dermatophytes and other filamentous fungi. J. Antimicrobial. Chemotherapy, 50, 195-199.

[18] Diane HC, Sanchez CJ and Mende K. (2015). In vitro activity of Melaleuca alternifolia (tea tree) oil on filamentous fungi and toxicity to human cells. Medical Mycology, 53, 285-294.

[19] González-José R, Ignacio E, Walter AN, Ruben C and Hectop MP. (2008). Cladistic analysis of continuous modularized traits provides phylogenetic signals in Homo evolution. Nature, 453, 775-778.

[20] Trease GE and Evans WC. (1989). Pharmacology, 11th Edition. London, Bailliere Tindall Ltd., 60.

[21] Stein AC, Sortino M, Avancini C, Zacchino S and Von Poser G. (2005). Ethno-veterinary medicine in the search of antimicrobial agents: Antifungal activity of Pterocaulon (Asteraceae). J. Ethanopharmacology, 99, 211-214.

[22] Wayne PA. (2007). Performance Standards for antimicrobial susceptibility testing, seventeenth informational supplement. National Clinical and Laboratory Standards Institute (NCLSI), M100-S17, 
[23] Obuotor EM and Onajobi FD. (2000). Preliminary evaluation of cytotoxic properties of Raphia hookeri fruit mesocarp. Fitoterapia, 71(2), 190-192.

[24] Maclaughin Jl, Chnag CJ and Smith Dl. (1991). "Bench-Top" Bioassays for the discovery of Bioactive Natural Product: An update (Atta Ur-Rahman Ed), Studies in natural product Chemistry. Elsevier Science Publisher, B.V. Amsterdam, 9, 101-103.

[25] Jose VM, Bhalla A, Sharma N, Hota D, Sivaprasad S and Pandhi P. (2007). Study of association between use of complementary and alternative medicine and non-compliance with modern medicine in patients presenting to the emergency department. Journal of Postgraduate Medicine, 53(2), 96-101.

[26] Marks DF. (2016). Dyshomeostasis, obesity, addiction and chronic stress. Health.Psychol Open, 3(1), 20-55.

[27] Gorinstein S, Martín-Belloso O, Park YS, Haruenkit R, Lojek A, Ĉ́íž M, Caspi A, Libman I and Trakhtenberg S. (2001). Comparison of some biochemical characteristics of different citrus fruits. Food Chem, 74, 309-315.

[28] Gagan S and Uttam SB. (2017). Pharmacognostic standardization of the leaf of Melaleuca alternifolia. African journal of traditional complementary and alternative medicine, 14(3), 1-11.

[29] Akrout A, El Jani H, Zammouri T, Mighri H and Neffati M. (2010). Phytochemical screening and mineral contents of annual plants growing wild in the southern of Tunisia. Journal of Phytology, 2(1), 034-040.

\section{How to cite this article}

Onyenwe NE, Adeniyi-Akee MA, Akpoyibo EJ, Nwofor CN and Okoro JC. (2020). Antimycotic effect of Melaleuca alternifolia on cutaneous mycosis. GSC Biological and Pharmaceutical Sciences, 11(2), 114-123. 